\title{
Scalar structure of turbulent partially-premixed dimethyl ether/air jet flames
}

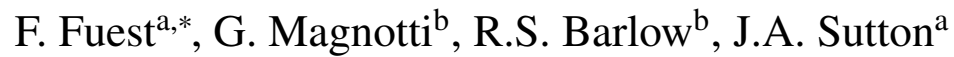 \\ ${ }^{a}$ Department of Mechanical and Aerospace Engineering, The Ohio State University, 201 W. 19th Avenue, Columbus, OH, USA \\ ${ }^{b}$ Sandia National Laboratories, 7011 East Avenue, Livermore, CA, USA
}

\begin{abstract}
This work presents results of temperature and major species measurements from two turbulent piloted, partially-premixed dimethyl ether (DME)/air jet flames with Reynolds numbers of 29,300 and 58,600. These results are intended to provide a first set of multi-scalar data from a new flame series for the investigation of turbulence-chemistry interaction and the validation of turbulent combustion models using a complex, oxygenated fuel, DME. The current work investigates two Reynolds number cases from the complete DME flame series (five flames) that were formulated to be similar to the well-known Sydney/Sandia piloted jet burner flame series A-F using methane fuels. The flame structure is examined using ensemble mean and rms radial profiles at various axial positions downstream of the nozzle exit as well as statistics conditioned on mixture fraction. Finally, selected results of the two cases are compared to the original methane-based configurations. Finite-rate chemistry effects such as local extinction and re-ignition and their impact on the scalar flame structure are found to be different in the DME/air jet flames as compared to the methane-based jet flames.
\end{abstract}

Keywords: dimethyl ether, partially-premixed, turbulent flames, 1D Raman scattering, model validation

\section{Introduction}

The validation of turbulent combustion models from benchmark experimental data sets has been a primary goal of the International Workshop on Measurement and Computation of Turbulent Flames (TNF) [1]. In order to provide experimental results on the flow field and the scalar structure of well-defined target flames, a variety of laser-based diagnostics have been applied. One important tool to gain information on the interaction between the turbulent flow field and the combustion chemistry is 1D Raman/Rayleigh scattering. Comprehensive data sets of temperature, major species $\left(\mathrm{CO}_{2}, \mathrm{O}_{2}, \mathrm{CO}, \mathrm{N}_{2}, \mathrm{CH}_{4}, \mathrm{H}_{2} \mathrm{O}, \mathrm{H}_{2}\right)$, and derived quantities, such as mixture fraction, and their gradients

\footnotetext{
${ }^{*}$ Corresponding author

Email address: fuest.1@osu.edu (F. Fuest)
} 
have been used in various turbulent flames to assess and validate turbulent combustion models [2]. In recent years, there have been efforts made to extend these diagnostic methods to fuels with increased complexity as compared to the predominately studied hydrogen and methane flames. Dimethyl ether (DME) has been selected as a promising target fuel, primarily due to its low tendency to form soot and consequently, its accessibility by 1D Raman/Rayleigh measurements [3, 4]. Frank and coworkers [5, 6] introduced a series of partially-premixed DME/air flames following the well-documented methane/air flame series A-F in the Sydney/Sandia piloted jet burner geometry [7, 8].

In this work we present experimental results from 1D Raman/Rayleigh/CO-LIF measurements of seven major species $\left(\mathrm{CO}_{2}, \mathrm{O}_{2}, \mathrm{CO}, \mathrm{N}_{2}\right.$, DME, $\left.\mathrm{H}_{2} \mathrm{O}, \mathrm{H}_{2}\right)$ and temperature from two turbulent flames DME-D and DME-F, which correspond to Reynolds numbers of 29,300 and 58,600, respectively. These flame conditions represent the lowest and second highest Reynolds number (based on nozzle diameter) within the new DME flame series. The experimental setup and details concerning accompanying laminar flame calculations are described in Section 2. Results, including mean/rms temperature and mixture fraction radial profiles at six downstream locations, as well as conditionallyaveraged statistics, are presented in Section 3. A summary and concluding remarks are given in Section 4.

\section{Experimental method}

Simultaneous 1D Raman/Rayleigh scattering and CO laser induced fluorescence (CO-LIF) were used to measure instantaneous species concentrations and temperature at the Combustion Research Facility of the Sandia National Laboratories $[4,9,10]$. Four sequentially-fired frequency-doubled Nd:YAG lasers operating at $532 \mathrm{~nm}$ were used to determine species mole fractions and temperature along a $6 \mathrm{~mm}$-line segment via spontaneous Raman/Rayleigh scattering. In addition, an Nd:YAG-pumped tunable dye laser was used for the simultaneous CO-LIF measurement. For the Raman/Rayleigh measurements, optical pulse stretchers and reduced laser power were used to avoid optical breakdown at the probe volume, where a combined energy of $1 \mathrm{~J} /$ pulse at $532 \mathrm{~nm}$ was focused by a lens with a focal length of $500 \mathrm{~mm}$ to a projected beam waist of $\sim 200 \mu \mathrm{m}$ as determined from the width at $1 / \mathrm{e}^{2}$ from the Rayleigh scattering image. Laser energy fluctuations were monitored using a thermoelectric joule meter. The precision in the Rayleigh temperature measurement vary between $0.25 \%$ and $1 \%$ for room and flame temperatures, respectively.

The emitted Raman, Rayleigh, and CO-LIF light is collected with a combination of $\mathrm{f} / 2$ and $\mathrm{f} / 4$ achromats and 
focused into a custom spectrometer as described in [11]. Within the spectrometer, the Raman, Rayleigh, and CO-LIF signals were separated by dichroic beam splitters. In order to reduce the crosstalk of depolarized broadband and $\mathrm{C}_{2}$-fluorescence interferences and chemiluminescence, the Raman-scattered light passed through a thin-film polarizer before dispersion via a high-transmission grating (1200 lines/mm). A low-noise cryogenically-cooled CCD camera (Roper Scientific, VersArray 1300) in conjunction with custom-built rotating wheel shutters, were used to collect the dispersed Raman signals from 550-700 nm with exposure times as short as 3.9 $\mathrm{\mu s}$ (FWHM). The data was acquired using spectral and spatial hardware on-chip binning to decrease camera readout noise and readout time $[10,12]$. In the spatial direction a ten-pixel on-chip binning was applied, yielding sixty spatial Raman superpixels along the line segment with a spatial resolution of $102.6 \mu \mathrm{m} /$ pixel. The images were processed using the hybrid matrix inversion method with extensions for processing DME-data as outlined in $[4,3,10]$. One laminar flame calculation was used to derive Raman response and crosstalk curves and a temperature-dependent Rayleigh scattering cross section model to account for DME decomposition into smaller hydrocarbon molecules which were not measured separately. This adds additional uncertainties to the species and temperature measurements with a peak uncertainty around $1400 \mathrm{~K}$ as shown in $[4,3]$. For example, the uncertainty in the temperature measurement around $1400 \mathrm{~K}$ is increased from $\pm 2 \%$ to $\pm 5 \%$. Air, cold gases diluted with nitrogen, and laminar methane/air flat flames were used for calibration of species signals and temperature.

Piloted turbulent DME/air jet flames, as introduced previously by Frank and coworkers [5, 6], with a stoichiometric value of the mixture fraction of $\xi_{\mathrm{st}}=0.35$ were investigated in the burner configuration of the Sydney/Sandia piloted flame series A-F $[8,13,14,15,16,17]$. The inner diameter of the main jet tube was measured as $d=7.45 \mathrm{~mm}$, the pilot annulus inner and outer diameter were $8 \mathrm{~mm}$ and $18.2 \mathrm{~mm}$, respectively, and the co-flow was $25.4 \mathrm{~cm} \times 25.4 \mathrm{~cm}$. In the current work, results of DME flame D and F are presented. Table 1 gives the unburnt gas compositions for the main jet, pilot, and co-flow. Table 2 gives the operating conditions (bulk velocity and Reynolds number) of the main jet, pilot, and co-flow for the two flames. Pilot flows of $\mathrm{C}_{2} \mathrm{H}_{2}, \mathrm{H}_{2}$, air, $\mathrm{CO}_{2}$, and $\mathrm{N}_{2}$ are selected to match the product composition and temperature of a premixed DME-air flame at 0.6 equivalence ratio, but with higher flame speed.

Laminar flame calculations were conducted using CHEM1D $[18,19,20,21]$ and the DME reaction mechanism from Zhao et al. [22]. Experimental results are compared to calculations at two strain rates based on the equal Lewis 
number assumption $(\mathrm{Le}=1)$ for all species. For all comparisons mixture fraction was derived consistently from species mole fractions for both the experimental data and the calculations. The important intermediate species, which were not measured in the experiment $\left(\mathrm{CH}_{2} \mathrm{O}, \mathrm{CH}_{4}, \mathrm{C}_{2} \mathrm{H}_{2}, \mathrm{C}_{2} \mathrm{H}_{4}, \mathrm{C}_{2} \mathrm{H}_{6}\right.$ and $\left.\mathrm{CH}_{3}\right)$, were treated as outlined in $[3,4]$ to derive the adapted mixture fraction $\xi_{6+(5)}^{*}$ in order to provide a consistent comparison of the data from the experiment and the calculations. Deviations of the adapted mixture fraction from the original Bilger formulation [23] primarily occur in the mixture fraction range of 0.4-0.8. Although for laminar calculations used in this work deviations are relatively small $(<5 \%)$, comparisons between species mass fractions and numerical simulations should be treated with caution in these regions. Note that in particular accumulated hydrocarbon mass fractions from DME and intermediate hydrocarbons can increase by a factor of more than two when converted from measured mole fractions because of significant differences in molar masses of DME and intermediate hydrocarbons [3, 4].

\section{Results and discussion}

Data in the turbulent DME/air flames were acquired at six axial positions of $\mathrm{x} / \mathrm{d}=1,5,7.5,10,20$, and 40 and sufficient radial positions (at each axial location) to cover the full composition space of the flame. Figures 1 and 2 show results for the flames DME-D and DME-F in terms of spatial means (top row) and their corresponding rms values (bottom row) for mixture fraction and temperature versus normalized radial position $\mathrm{r} / \mathrm{d}$, where $\mathrm{d}$ is the nozzle diameter. The mean and rms values were computed from data sets with as many as 1800 single-shot measurements. Rayleigh scattering was used for all temperature measurements except for data at $\mathrm{x} / \mathrm{d}=1$, which were slightly affected by background elastic scattering from the burner nozzle. At these locations temperature from the Raman scattering measurements of number density is reported.

Generally, differences in the mean values between the two Reynolds number conditions are small, with larger differences in the rms values. At $\mathrm{x} / \mathrm{d}=1$, there are notable differences for the temperature and mixture fraction profiles between DME-D and DME-F at the radial position corresponding to the interface between the jet and pilot. The increased bulk velocity of DME-F seems to affect the reaction progress and the mixing in physical space. Temperature, as well as mixture fraction, profiles (mean and rms) are wider in the DME-D case than in the DME-F case. Higher shear between the pilot and co-flow within DME-F is apparent as noted by the higher peak rms values at $\mathrm{r} / \mathrm{d}=1.15$. 
The impact of increased intermittency between the jet and the co-flow at $\mathrm{x} / \mathrm{d}=5$ is observed as a significantly higher second peak in the rms profile of temperature and a wider peak of the rms profile of mixture fraction. This also affects the mean peak temperature as evident by the $200 \mathrm{~K}$ decrease from flame DME-D to DME-F. From $\mathrm{x} / \mathrm{d}=$ 7.5 to 10 the second peak in the rms temperature profile of DME-D approaches the same magnitude as in DME-F. However, the mean and rms profiles for temperature and mixture fraction of DME-F are still broader by up to $0.5 \mathrm{r} / \mathrm{d}$ as compared to DME-D, even though the width of the mixing layer and flame brush is continuously increasing for both flames. While rms values on the centerline increase with increasing axial position, the centerline mean values remain constant for axial positions less than $x / d=20$. Differences between the two DME flames at $x / d=20$ and 40 are small and, in particular for the rms values, are within the measurement uncertainty due to larger $\mathrm{C}_{2}$ interferences, background luminosity, and increased effects of beam steering at these axial location.

Figure 3 shows the conditional mean values for seven major species and temperature for flames DME-D and DME-F. Data from axial locations $\mathrm{x} / \mathrm{d}=1,5$, and 40 are compared to laminar flame calculations at strain rates of $100 \mathrm{~s}^{-1}$ and $2300 \mathrm{~s}^{-1}$; the latter value corresponding to the maximum possible strain rate prior to the extinction limit. The observed trends between different axial locations and the two Reynolds number cases are consistent amongst all scalars. The conditioned scalar profiles shift to higher mixture fraction values, both intermediates $\left(\mathrm{CO}\right.$ and $\left.\mathrm{H}_{2}\right)$ and products $\left(\mathrm{CO}_{2}\right.$ and $\left.\mathrm{H}_{2} \mathrm{O}\right)$ have lower peak values, and $\mathrm{O}_{2}$ and $\mathrm{N}_{2}$ have higher minimum values for increasing axial position.

There are several factors that influence the behavior of the conditional mean results, including the very significant influence of the pilot at $\mathrm{x} / \mathrm{d}=1$, the relative importance of molecular diffusion and turbulent transport, which varies with Reynolds number and downstream distance, and local effects of high strain or scalar dissipation on reaction progress. Therefore, the Le $=1$ laminar calculations are not expected to represent all features of the measurements. At $\mathrm{x} / \mathrm{d}=1$ the pilot condition $(\phi=0.6)$ establishes a boundary condition for both the mixing layer between pilot and air and the reaction zone between pilot and jet fluid. This is evident from Fig. 1. The expected structure of the reaction zone at $\mathrm{x} / \mathrm{d}=1$ would be similar to a strained diffusion flame with the lean boundary condition being that of the pilot, not air, which is consistent with results in Fig. 3. At $x / d=1$ there are large differences between results for flames DME-D and DME-F, with progress of reaction being significantly lower in flame DME-F due to higher strain 
and scalar dissipation rates.

Already at $\mathrm{x} / \mathrm{d}=5$ the influence of the pilot on conditional mean structure is much reduced, and conditional mean profiles from flames DME-D and DME-F show behavior that falls mostly in between the two laminar flame calculations $\left(100 \mathrm{~s}^{-1}\right.$ and $\left.2300 \mathrm{~s}^{-1}\right)$. In particular, the trends for $0.6<\xi<1.0$ are reasonably well represented by the $\mathrm{Le}=1$ assumption, due to high levels of turbulence in this part of the jet. Farther downstream, at $x / d=40$, the measured conditional means have shifted toward the laminar flame calculations at the lower strain rate of $100 \mathrm{~s}^{-1}$. The calculation shows a shoulder in the temperature profile at very rich conditions $(0.8<\xi<0.9)$ indicating an important level of heat release. Flame DME-D results extend more in this direction than flame DME-F, as expected for the lower Reynolds number flame.

The $\mathrm{CO}$ and $\mathrm{H}_{2}$ mole fractions continuously increase with increasing axial location. At $\mathrm{x} / \mathrm{d}=40$, the peak $\mathrm{H}_{2}$ and $\mathrm{CO}$ mole fractions are as high as 0.10 and 0.14, respectively. Based on the results of Fig. 3, the Reynolds-number (or Damköhler number) effects vary depending on the axial location, indicating varying degrees of turbulence-chemistry interaction. At $\mathrm{x} / \mathrm{d}=1$ and downstream at $\mathrm{x} / \mathrm{d}=40$, the higher velocity of DME-F $(2 \times$ higher than that of DMED) appears to lead to a reduction in overall chemical reaction (e.g., lower peak temperature and intermediate mole fractions) as compared to DME-D. However, at intermediate axial locations (i.e., $\mathrm{x} / \mathrm{d}=5$ as well as $7.5,10$, and 20 which are not shown), turbulent mixing and chemical kinetic effects are well balanced as evident by the similarity between the DME-D and DME-F profiles. The two-fold increase in fuel consumption per unit time of DME-F does not appear to affect the mixing process significantly nor does the reaction chemistry appear to be affected by the smaller turbulent time and length scales as compared to the low Reynolds number case. Completely unreacted samples are no longer found at the downstream location $\mathrm{x} / \mathrm{d}=40$ and significant reaction progress is observed around $\xi=1$. Note that the mixture fraction in DME/air laminar flame calculations with multicomponent transport can exceed unity before decreasing toward the reaction zone [3]. The behavior of the richest samples at $\mathrm{x} / \mathrm{d}=40$ in these jet flames may be an effect of differential diffusion, but further work will be needed to establish this connection.

Figure 4 shows scatter plots at $\mathrm{x} / \mathrm{d}=7.5$ of DME+ (including intermediate hydrocarbons) and $\mathrm{H}_{2} \mathrm{O}$ from both DME flames (left column). In addition, the right column displays scatter plots of $\mathrm{CH}_{4}$ and $\mathrm{H}_{2} \mathrm{O}$ from two wellcharacterized methane flames, $\mathrm{CH}_{4}-\mathrm{D}$ and $\mathrm{CH}_{4}-\mathrm{F}$, corresponding to the same mass flow rates as the DME flames. In 
order to provide a consistent comparison between the $\mathrm{DME}$ and $\mathrm{CH}_{4}$ flames, the scatter plots are constructed using a consistent number of samples.

Significantly less local extinction is apparent in the DME flames as compared to the corresponding $\mathrm{CH}_{4}$ flames. For the $\mathrm{CH}_{4}-\mathrm{F}$ flame, the high number of local extinction events strongly affects the conditional mean values, whereas the effects are much less in the DME-F flame. In fact, the level of local extinction in DME-F more closely resembles the level of local extinction of $\mathrm{CH}_{4}$-D. The scatter plots also show interesting features in terms of scalar structure. Steeper gradients are observed in the DME flames for both DME+ and $\mathrm{H}_{2} \mathrm{O}$ for conditions corresponding to $0.85<$ $\xi<1$. It also is noted that DME+ is mostly consumed under very rich conditions $(\xi=0.6)$ whereas $\mathrm{CH}_{4}$ extends further towards $\xi=0.4$. For the DME flames, the rich consumption leads to significant formation of $\mathrm{H}_{2}$ and $\mathrm{CO}$ (see Fig. 3) away from the stoichiometric contour $\left(\xi_{\text {st }}=0.35\right)$. The formation of smaller, highly reactive intermediates on the rich side leads to faster reaction chemistry and consequently more robustness against local extinction as compared to the methane flames. In addition, the higher upper flammability limit of DME and the smaller DME/air ratio which was selected to match $\xi_{\text {st }}$ of the methane flames also favors flame robustness since the DME flames are closer to the premixed regime. Based on laminar flame calculations, the extinction strain rate for a partially premixed DME flame at the present conditions is roughly 1.5 times that for the $\mathrm{CH}_{4}$ conditions.

Local extinction is dependent on the fuel type, bulk velocity, details of the pilot and spatial location within the flame. Figure 5 shows conditional probability density functions (cPDFs) of $X_{\mathrm{H}_{2} \mathrm{O}}$ at different axial locations for the DME (left column) and $\mathrm{CH}_{4}$ (right column) flames for comparison. Samples from a mixture fraction range of $0.3<\xi<0.6$ and bins of 0.01 mole fraction were chosen for the cPDFs. For this study, $\mathrm{H}_{2} \mathrm{O}$ was selected instead of temperature because it is less prone to systematic errors due to the use of a temperature-dependent Rayleigh scattering cross section model in the data evaluation $[4,3]$. However, as temperature and $X_{\mathrm{H}_{2} \mathrm{O}}$ are well correlated quantities $\left(\mathrm{H}_{2} \mathrm{O}\right.$ marks the reaction progress), the conclusions drawn from the cPDFs shown in Fig. 5 are identical irrespective of the choice of $T$ or $X_{\mathrm{H}_{2} \mathrm{O}}$. Consistent with the comparison in Fig. 4 flame DME-D (black) and DME-F (red) are primarily compared to flame $\mathrm{CH}_{4}-\mathrm{D}$ (black) and $\mathrm{CH}_{4}-\mathrm{F}$ (red) although results from $\mathrm{CH}_{4}-\mathrm{C}_{\text {and }} \mathrm{CH}_{4}-\mathrm{E}$ are shown for completeness. In general, the DME flames are only affected slightly by the increase in velocity from flame DME-D to DME-F, whereas the $\mathrm{cPDFs}$ of $\mathrm{CH}_{4}-\mathrm{D}$ and $\mathrm{CH}_{4}-\mathrm{F}$ show significant differences. Most apparent, at $\mathrm{x} / \mathrm{d}=15$, is the 
transition from a single-peak profile to bimodal structure when going from $\mathrm{CH}_{4}-\mathrm{D}$ and $\mathrm{CH}_{4}-\mathrm{F}$, where the majority of samples are in the low and intermediate mole fraction range. This behavior is not observed for the DME flames. The small differences between DME-D and DME-F apparent at $\mathrm{x} / \mathrm{d}=7.5$ decrease with increasing downstream position and disappear at $\mathrm{x} / \mathrm{d}=20$, indicating negligible occurrences of local extinction. This behavior is similar to that observed within $\mathrm{CH}_{4}-\mathrm{D}$ in contrast to the $\mathrm{CH}_{4}-\mathrm{F}$ case which indicates a large number of local extinction events still occur at $\mathrm{x} / \mathrm{d}=30$.

Figure 6 shows ensemble averages for mixture fraction and temperature on the centerline of the jet for the DME and $\mathrm{CH}_{4}$ flames. No significant differences between the two DME cases D and $\mathrm{F}$ are observed at the first five measured axial locations for both temperature and mixture fraction. At of $\mathrm{x} / \mathrm{d}=40$ a small difference of $80 \mathrm{~K}$ is observed. Although centerline mixing progress in the DME cases is significantly decreased as compared to the $\mathrm{CH}_{4}$ cases, the reaction progress is very similar. As suggested by simple scaling laws for flame lengths, see e.g. [24, 25], this can be, at least partly, attributed to the higher density of the DME/air mixture as compared to the $\mathrm{CH} 4 /$ air mixture.

\section{Summary and Conclusions}

Results from 1D Raman/Rayleigh/CO-LIF measurements of major species and temperature were used to examine the flame structure within two turbulent partially-premixed, piloted DME/air jet flames operating at Reynolds numbers of 29,300 and 58,600, respectively. Ensemble mean and rms radial profiles were presented as a function of axial position along with statistics conditioned on the mixture fraction. Measurements at six axial positions were examined. The impact of the Reynolds number on shear layer and flame brush was shown in spatial mean and rms profiles of temperature and mixture fraction. Large similarity was found in mean profiles, whereas rms profiles showed significant differences in widths and rms peak values for axial locations of $\mathrm{x} / \mathrm{d} \leq 10$. Only minor differences remained at $\mathrm{x} / \mathrm{d}=20$, and 40 .

Further insights into the structure of the DME/air flames were derived from conditional mean values of seven major species and temperature in mixture fraction space in comparison to laminar flame calculations of various strain rates. The lowest, measured axial location, $\mathrm{x} / \mathrm{d}=1$, revealed the impact of the pilot by a shift of the measured species and temperature profiles on the fuel-rich side beyond the laminar calculations with the highest strain rate. The 
comparison between different axial positions and the two Reynolds number cases showed the trend towards smaller strain rates with increasing axial position and decreasing Reynolds number. In contrast to the spatial mean and rms profiles, differences between the two Reynolds number cases were smallest at intermediate axial locations and largest at $\mathrm{x} / \mathrm{d}=1$, and 40 .

Finally, the current results were compared to existing data from the original piloted, methane flame series using scatter plots and conditional probability density functions. Significantly lower levels of local extinction events were found in the DME flames as compared to the methane flames. Mixing progress on the jet centerline was found decreased by up to $35 \%$ in the DME cases at $\mathrm{x} / \mathrm{d}=40$. This was partly attributed to the higher density of the DME/air mixture.

\section{Acknowledgements}

Work at Ohio State University was supported by the Combustion Energy Frontier Research Center funded by the US Department of Energy, Office of Science, BES under Award DE-SC0001198. Work performed at Sandia was supported by the Division of Chemical Sciences, Geosciences and Biosciences, Office of Basic Energy Sciences, US Department of Energy. Sandia National Laboratories is a multiprogram laboratory operated by Sandia Corporation, a Lockheed Martin Company, for the United States Department of Energy under contract DE-AC04-94-AL85000. The help of R. Harmon during the experiments is gratefully acknowledged.

\section{References}

[1] International Workshop on Measurement and Computation of Turbulent Nonpremixed Flames (TNF).

URL http://www.ca.sandia.gov/TNF

[2] R. S. Barlow, Laser diagnostics and their interplay with computations to understand turbulent combustion, Proc. Combust. Inst. 31 (1) (2007) $49-75$.

[3] F. Fuest, R. S. Barlow, J.-Y. Chen, A. Dreizler, Raman/rayleigh scattering and co-lif measurements in laminar and turbulent jet flames of dimethyl ether, Combust. Flame 159 (2012) 2533-2562.

[4] F. Fuest, 1D Raman/Rayleigh-scattering and CO-LIF measurements in laminar and turbulent jet flames of dimethyl ether using a hybrid data reduction strategy, Ph.D. thesis, Technische Universität Darmstadt, Germany (2011).

URL http: //tuprints .ulb.tu-darmstadt.de/2773/ 
[5] J. H. Frank., A. G. Hsu, J. Kuhl, Turbulent partially premixed dimethyl ether/air jet flames: A new series of target flames for experiments and modeling, Proceedings of TNF 10.

URL http://www.sandia.gov/TNF/10thWorkshop/TNF10.html

[6] B. Coriton, M. Zendehdel, S. Ukai, A. Kronenburg, O. T. Stein, S.-K. Im, M. Gamba, J. H. Frank, Imaging measurements and les-cmc modeling of a partially-premixed turbulent dimethyl ether/air jet flame, Proc. Combust. Inst. 35 (accepted).

[7] R. S. Barlow, J. H. Frank, G. J. Fiechtner, Comparison of co measurements by raman scattering and two-photon lif in laminar and turbulent methane flames, Spring Meeting of the Western States Section/Combustion Institute.

[8] R. S. Barlow, J. H. Frank, A. N. Karpetis, J.-Y. Chen, Piloted methane/air jet flames: Transport effects and aspects of scalar structure, Combust. Flame 143 (4) (2005) $433-449$.

[9] R. S. Barlow, M. J. Dunn, M. S. Sweeney, S. Hochgreb, Effects of preferential transport in turbulent bluff-body-stabilized lean premixed ch4/air flames, Combust. Flame 159 (8) (2012) 2563 - 2575.

[10] F. Fuest, R. S. Barlow, D. Geyer, F. Seffrin, A. Dreizler, A hybrid method for data evaluation in 1-d raman spectroscopy, Proc. Combust. Inst. 33 (1) (2011) $815-822$.

[11] R. S. Barlow, G. H. Wang, P. Anselmo-Filho, M. S. Sweeney, S. Hochgreb, Application of raman/rayleigh/lif diagnostics in turbulent stratified flames, Proc. Combust. Inst. 32 (1) (2009) 945 - 953.

[12] P. C. Miles, Raman line imaging for spatially and temporally resolved mole fraction measurements in internal combustion engines, Appl. Opt. 38 (9) (1999) 1714-1732.

[13] R. S. Barlow, J. H. Frank, Effects of turbulence on species mass fractions in methane/air jet flames, Proc. Combust. Inst. 27 (1998) $1087-1095$.

[14] C. Schneider, A. Dreizler, J. Janicka, E. P. Hassel, Flow field measurements of stable and locally extinguishing hydrocarbon-fuelled jet flames, Combust. Flame 135 (1-2) (2003) 185-190.

[15] A. N. Karpetis, R. S. Barlow, Measurements of scalar dissipation in a turbulent piloted methane/air jet flame, Proc. Combust. Inst. 29 (2002) 1929-1936.

[16] R. S. Barlow, A. N. Karpetis, Measurements of scalar variance, scalar dissipation, and length scales in turbulent piloted methane/air jet flames, Flow Turbul. Combust. 72 (2004) 427-448.

[17] R. S. Barlow, H. C. Ozarovsky, A. N. Karpetis, R. P. Lindstedt, Piloted jet flames of $\mathrm{ch}_{4} / \mathrm{h}_{2} /$ air: Experiments on localized extinction in the near field at high reynolds numbers, Combust. Flame 156 (11) (2009) 2117 - 2128.

[18] CHEM1D 3.0 - A one-dimensional laminar flame code. Eindhoven University of Technology.

URL http://www. combustion.tue.nl.

[19] J. A. van Oijen, L. P. H. de Goey, Modelling of premixed laminar flames using flamelet-generated manifolds, Combust. Sci. and Techn. 161 (2000) 113 - 137.

[20] J. A. van Oijen, Flamelet-generated manifolds: Development and application to premixed laminar flames, Ph.D. thesis, Eindhoven University of Technology (2002).

URL http://www. combustion.tue.nl 
[21] H. Bongers, Analysis of flamelet-based methods to reduce chemical kinetics in flame computations, Ph.D. thesis, Eindhoven University of Technology (2005)

URL http://www. combustion.tue.nl

[22] Z. Zhao, M. Chaos, A. Kazakov, F. L. Dryer, Thermal decomposition reaction and a comprehensive kinetic model of dimethyl ether, Int. J. Chem. Kinet. 40 (2008) 1-18.

[23] R. W. Bilger, S. H. Stårner, R. J. Kee, On reduced mechanisms for methane-air combustion in nonpremixed flames, Combust. Flame 80 (2) (1990) $135-149$

[24] W. R. Hawthorne, D. S. Weddell, H. C. Hottel, Third Symposium on Combustion (1949) 266 - 288.

[25] M. A. Delichatsios, Combust. Flame (1993) 349 - 364.

Table 1. Unburnt gas compositions (in mole fractions) of the jet, pilot, and co-flow streams for the turbulent DME/air flames.

\begin{tabular}{lllllllll}
\hline & DME & $\mathrm{C}_{2} \mathrm{H}_{2}$ & $\mathrm{H}_{2}$ & $\mathrm{~N}_{2}$ & $\mathrm{O}_{2}$ & $\mathrm{Ar}$ & $\mathrm{H}_{2} \mathrm{O}$ & $\mathrm{CO}_{2}$ \\
\hline Jet & 0.2 & - & - & 0.6237 & 0.1673 & 0.0075 & 0.0008 & 0.0003 \\
Pilot & - & 0.0218 & 0.0878 & 0.6793 & 0.1718 & 0.0077 & 0.0012 & 0.0303 \\
Co-Flow & - & - & - & 0.7746 & 0.2078 & 0.0093 & 0.008 & 0.0004 \\
\hline
\end{tabular}

Table 2. Bulk velocities and Reynolds numbers of the turbulent DME/air flames.

\begin{tabular}{lllll}
\hline & $u_{\text {jet }}(\mathrm{m} / \mathrm{s})$ & $u_{\text {pilot }}(\mathrm{m} / \mathrm{s})$ & $u_{\text {co-flow }}(\mathrm{m} / \mathrm{s})$ & $R e_{\mathrm{d}}{ }^{\mathrm{a}}$ \\
\hline DME-D & 45.9 & 1.1 & 0.9 & 29,300 \\
DME-F & 91.8 & 2.1 & 0.9 & 58,600 \\
\hline
\end{tabular}

${ }^{\mathrm{a}}$ kinematic viscosity $v=1.167 \mathrm{E}-5 \mathrm{~m}^{2} / \mathrm{s}$ (private communication with Jonathan Frank). 

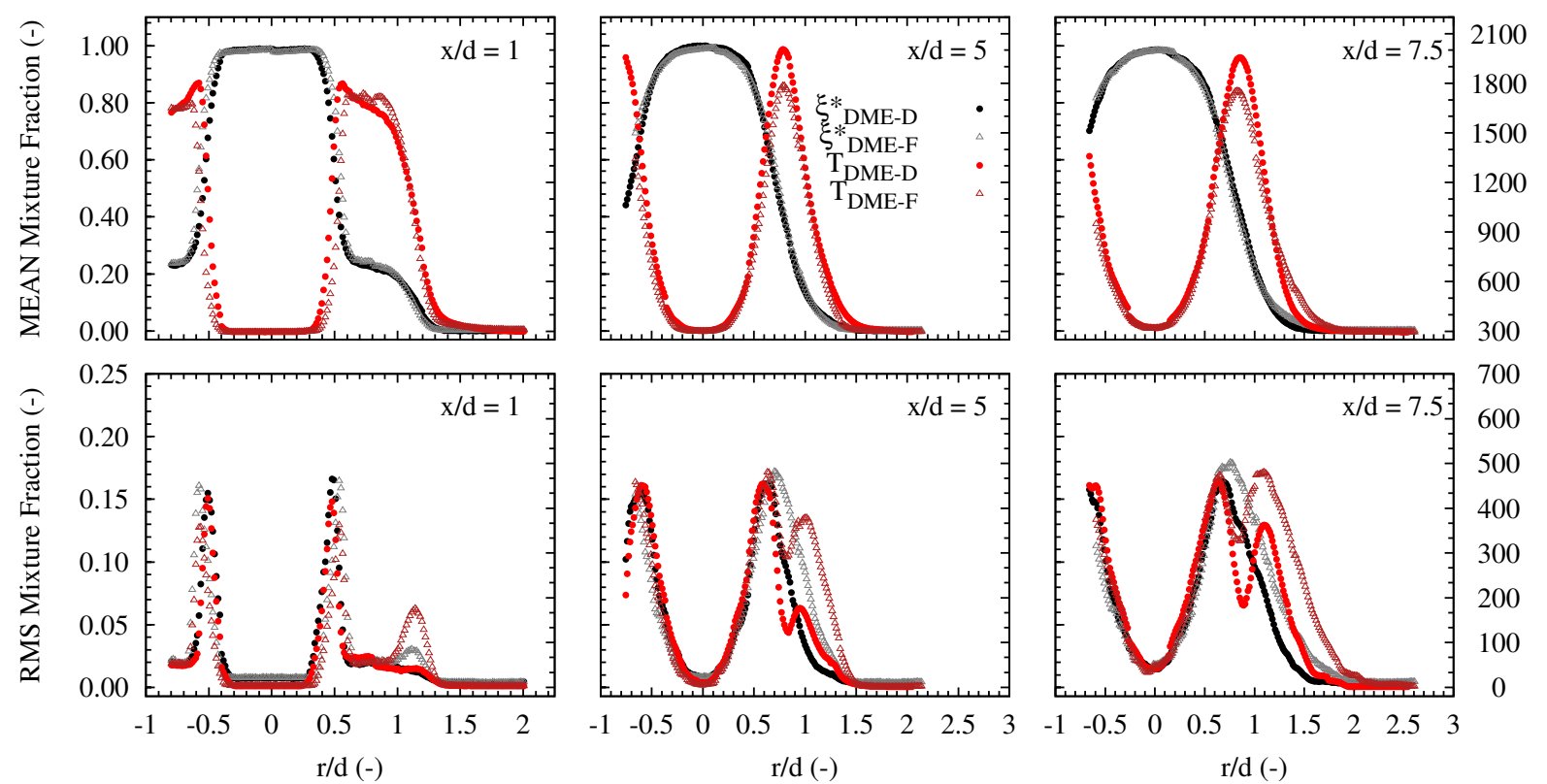

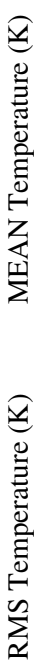

Figure 1. Spatial mean and rms values for temperature and mixture fraction at axial locations $\mathrm{x} / \mathrm{d}=1,5$, and 7.5 .
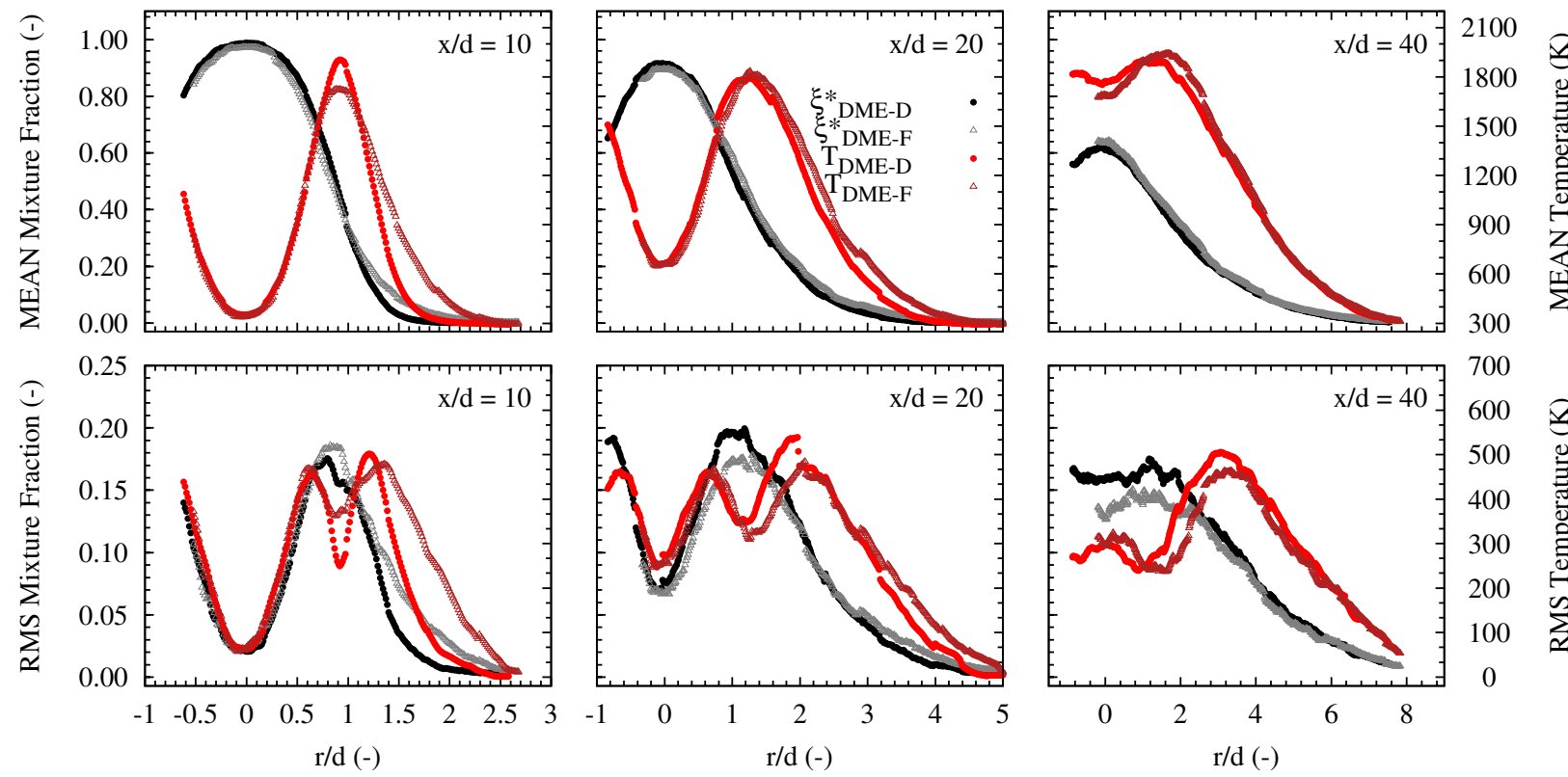

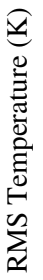

Figure 2. Spatial mean and rms values for temperature and mixture fraction at axial locations $x / d=10,20$, and 40 . 

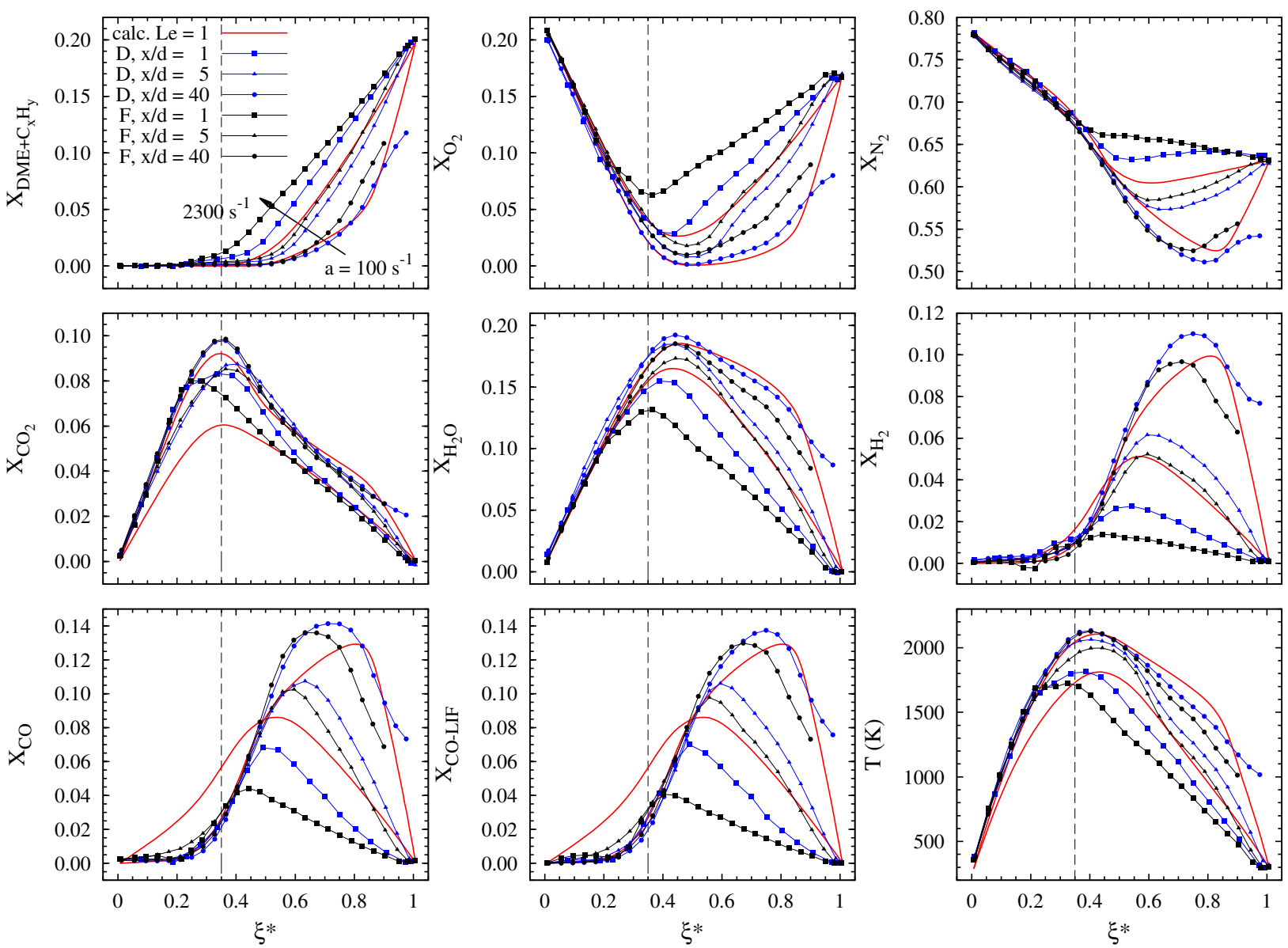

Figure 3. Conditional mean values for major species and temperature for flame DME-D (blue) and DME-F (black) at axial locations of $\mathrm{x} / \mathrm{d}=1,5$, and 40. Vertical dashed lines indicate the stoichiometric mixture fraction. 


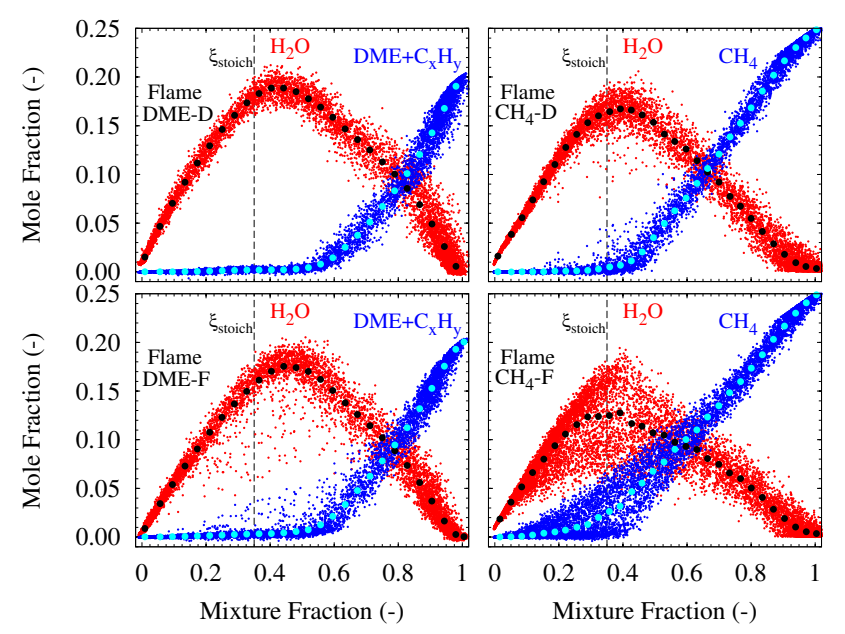

Figure 4. Scatter plots at $\mathrm{x} / \mathrm{d}=7.5$ of primary hydrocarbons $\left(\mathrm{DME}+\mathrm{C}_{\mathrm{x}} \mathrm{H}_{\mathrm{y}}\right.$ or $\left.\mathrm{CH}_{4}\right)$ and $\mathrm{H}_{2} \mathrm{O}$ conditioned on mixture fraction for DME-D and $\mathrm{F}$ as compared to $\mathrm{CH}_{4}-\mathrm{D}$ and $\mathrm{CH}_{4}$ from the Sandia series of partially-premixed $\mathrm{CH}_{4} /$ air jet flames [1].

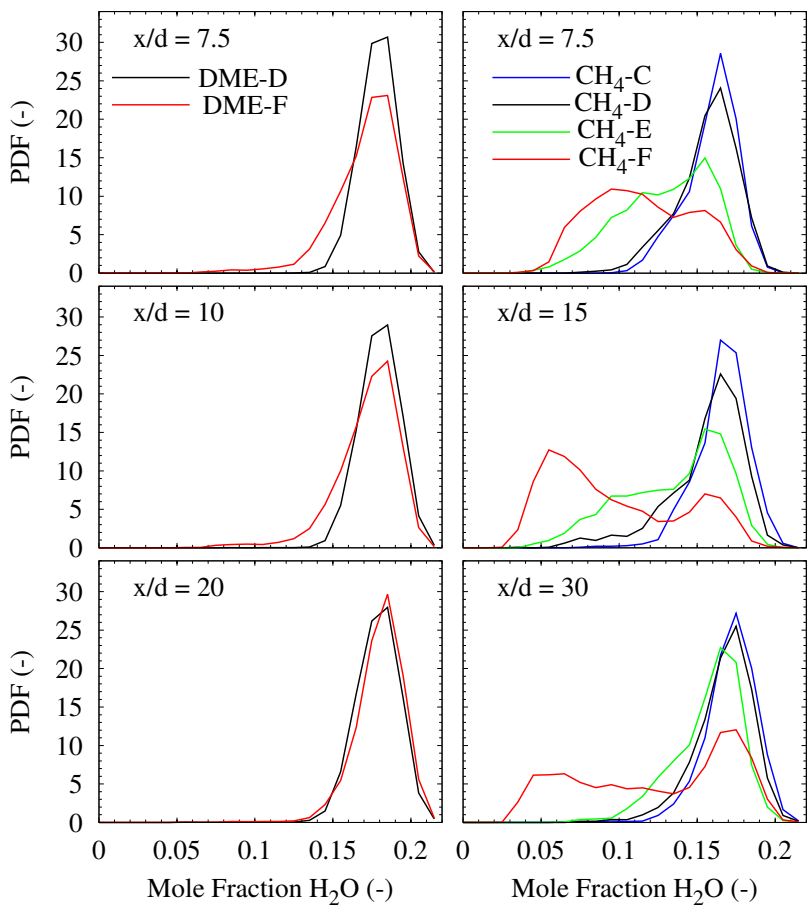

Figure 5. Conditional PDFs of $X_{\mathrm{H}_{2} \mathrm{O}}$ at axial locations $\mathrm{x} / \mathrm{d}=7.5,10$, and 20. For DME-D and F as compared to $\mathrm{CH}_{4}-\mathrm{C}, \mathrm{D}, \mathrm{E}$ and $\mathrm{F}$ [1]. 


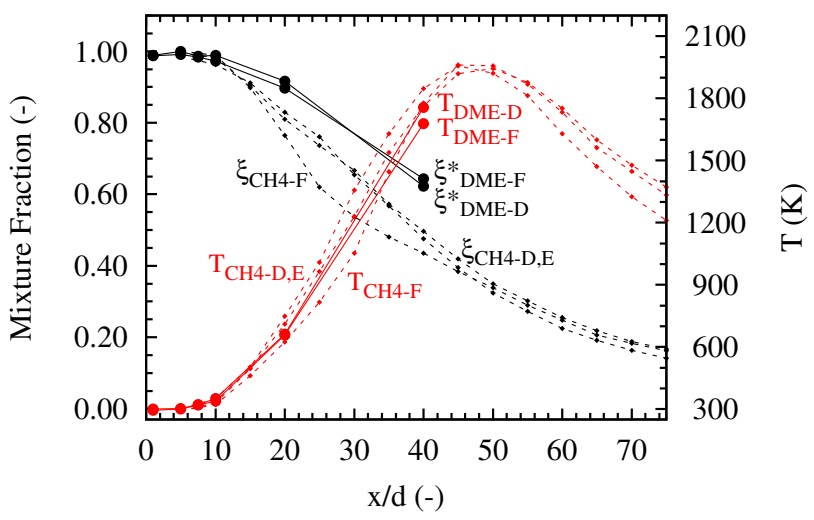

Figure 6. Mean centerline mixture fraction and temperature values for DME-D and $\mathrm{F}$ as compared to $\mathrm{CH}_{4}-\mathrm{D}, \mathrm{E}$ and $\mathrm{F}$ [1]. 